\title{
Introduction: empowering young people in disempowering times? Creating collaborative and transformative capabilities through participation
}

\section{Hans-Uwe Otto, Valerie Egdell, Jean-Michel Bonvin and Roland Atzmüller}

\section{SOCIAL DISADVANTAGE AND YOUNG PEOPLE IN EUROPE}

In many European countries, a large number of young people aged 15 to 29 years have challenging and complex educational or labour market experiences. Since the 2008 economic crisis, the situation of young people has again deteriorated dramatically in many European countries and in particular in southern and eastern Europe. Employment and training opportunities have reduced, and levels of poverty and social exclusion have increased, not only, but especially, for young people. Thus, the question is emerging as to whether young people are a group at great risk of becoming, being and staying socially disadvantaged. It is this problem of the social disadvantage of young people in Europe in the aftermath of the economic crisis that this volume focuses upon.

After having peaked in the immediate years after the beginning of the financial crisis in 2008 and the subsequent sovereign debt crisis in a range of European countries, the unemployment rate in the EU-28 for the 15 to 19 years age group stood at 24.6 per cent, ${ }^{1}$ for the 20 to 24 years age group at 19.1 per cent, and at 12.4 per cent for the 25 to 29 years age group. ${ }^{2}$ With the remarkable exception of Germany, Austria and Switzerland, who experienced a temporary peak of youth unemployment in the years preceding the crisis of 2008 (albeit on levels way below the situation in the so-called European periphery), in most European countries youth unemployment had remained relatively stable since the early 2000 s - although a high degree of variation between European member states has to be taken into account. 
Thus, the extent to which (different groups of) young people are affected by unemployment also varies across different countries. In 2015 the highest unemployment rates for the 15 to 19 years age group were observed in Greece (58.9 per cent), Spain (67.3 per cent) and Italy (60.4 per cent), while Germany (7.9 per cent), Austria (11.5 per cent) and Switzerland (8.8 per cent) were among the countries with the lowest rates of unemployment for this age group (Eurostat 2015). The figures for the first group of countries refer to unemployment rates representing a twofold (Italy) or almost threefold (Spain, Greece) increase since the years before the crisis set in. In countries such as Germany, Austria and Switzerland the unemployment rates of this age group remained rather stable throughout the crisis pointing towards some peculiarities of their VET (vocational education and training) and transition system from education to employment.

According to Eurostat data, in 2015 about 14.8 per cent of young people (aged 15 to 29 years) from the EU-28 were not in employment, education or training (NEET). Again the situation varies considerably between European member states. Whereas countries such as Germany (8.5 per cent), Denmark (7.7 per cent), the Netherlands (6.7 per cent), Switzerland (7.2 per cent) and Austria (8.7 per cent) had a relatively stable NEET rate below 10 per cent during the crisis years (even experiencing some decline over the last 10 years - as in the case of Germany) countries such as Greece (24.1 per cent), Italy (25.7 per cent), Spain (19.4 per cent) and Romania (20.9 per cent) had rates which stood between one fifth and one quarter of young people (Bacher 2014). These figures reveal considerable increases of the NEET rate in eastern and southern European countries over the last 10 years (Greece: +9.3 per cent since 2008; Italy: +6.9 per cent since 2007 ; Spain: +6.6 per cent since 2007; Romania +7.7 per cent since 2007).

The picture shifts and is in comparison to the unemployment figures slightly less polarized, but not less worrying, when European data about the share of young people (aged 15 to 24) at risk of poverty and social exclusion is taken into account. The share of young people at risk of poverty and social exclusion amounted to 30.9 per cent in European member states in 2015. Within the Euro-area the total amount of young people at risk of poverty and social exclusion increased by about 5.5 million since 2008. In a range of eastern and southern European countries like Greece (49.7 per cent), Romania (47.0 per cent) Spain (42.0 per cent) and Italy ( 36.5 per cent), and surprisingly Denmark ( 36.8 per cent) a very high proportion of young people were at risk of poverty and social exclusion. In countries such as Spain $(+18.3$ per cent) and Greece $(+16.5$ per cent) the figures for 2015 reveal a massive increase since the years immediately before the crisis.

Surprisingly also in countries such as Austria (20.9 per cent), Germany 
(23.1 per cent), Belgium (25.5 per cent), Netherlands (28.6 per cent) and France ( 24.5 per cent) the share of young people at risk of poverty and social exclusion was quite considerable. Whereas in Austria (+5.2 per cent increase since 2007), Denmark ( +6.5 per cent increase since 2008), Belgium $(+4.8$ per cent increase since 2009$)$, Netherlands $(+6.9$ per cent increase since 2007) and the UK (+8.9 per cent increase since 2009) the rate of young people at risk of poverty and social exclusion has increased since the beginning of the crisis, in Germany and Switzerland there was actually a reduction over this period and in France, it remained more or less stable. Furthermore, only in Switzerland (15.6 per cent) did the share of young people at risk of poverty and social exclusion remain below 20 per cent. With the exception of Germany, France and Switzerland these data reveal a deterioration of young people's situation since the years before the crisis, eradicating the slow progress some countries made in reducing the number of young people at risk of poverty and social exclusion in the years before. In particular for those southern and eastern European countries that had been hit hardest by the crisis and the subsequent strategies to tackle it through austerity oriented measures (welfare cuts) the figures raise the question of whether the rate of young people at risk of poverty and social exclusion (affecting up to 50 per cent of young people) has a new quality through which being young in itself becomes a social problem. For other countries the economic crisis tendencies and the volatility of growth rates represent severe obstacles to improve the situation of young people at risk of poverty and social exclusion in a sustainable way, seemingly leading to the creation of a more or less stable group of socially excluded youth.

However, the social disadvantages experienced by young people in Europe since the economic crisis go far beyond labour market and income situations. Young people are not only disadvantaged in 'objective' and 'quantifiable' terms such as their employment rates, educational outcomes or VET activities. Disadvantage also refers to other aspects and dimensions of social integration and participation which can encompass a range of areas including family formation, recognition and belonging to certain communities, social integration and discrimination, and political participation (Groenemeyer and Hoffmann 2014). Thus, young people may also be disadvantaged from a 'subjective' point of view in terms of their motivation and aspiration; their abilities to project their future lives and make meaningful plans concerning future careers as well as family formation or lifestyle choices; and their ability to participate in politics and society. These subjective disadvantages can have a profound effect on young people's transition from education to employment in terms of being able to find a training place or sustainable employment for example. Inequalities exist not only between young people and other cohorts, but also between 
young people themselves. Thus, there is a need to take a wide and nuanced view of disadvantage.

It is this key premise upon which this volume and its analysis are based. ${ }^{3}$ The multiple disadvantages experienced by some young people and the constraints to the opportunities available to them, may not be adequately understood if an intersectional and cumulative perspective is not taken. However, understandings of youth disadvantage need to go beyond individual attributes and deficits. Given the current dominance of supply-side oriented concepts of labour market dynamics there is a tendency in policy discourses and public debates to ascribe the situation of disadvantaged young people to their individual deficits and lifestyle choices (Blossfeld, Bertoloni and Hofäcker 2011; Coppola and O'Higgins 2016; Eriksson and Vogt 2013; Thompson 2011; van Berkel and Valkenburg 2007). This is complemented by assumptions about the alleged inability, or even unwillingness, of their families to convey and teach certain values and attitudes towards education and employment to their offspring. Thus more often than not unemployment, low educational achievements or poverty as well as limited political and social participation of young people are understood to be the result of a lack of motivation and work ethic, as well as inadequate parenting in allegedly dysfunctional families which are unwilling to foster their children in an adequate way (Saraceno 2015). Such an approach to disadvantage puts the burden of responsibility on young people themselves and their families, and discards the impact of other socio-structural parameters.

Youth disadvantage also needs to be situated within factors associated with the wider socio-economic conditions such as the policy landscape, the education system, the legal framework, the development of employment conditions and the quality of jobs. Demand side and macroeconomic issues need to be taken into account. In addition, normative expectations about the place of young people in society (for example, economy, politics and civil society) need to be accounted for. These frames of reference are incorporated into institutional devices such as schools, active labour market programmes, public policies, and the like. Hence, a multidimensional evaluation of youth disadvantage is required. The interrelation between young people's labour market, educational, social and political participation also varies between socio-economic contexts, thus youth inequalities need to be explained in connection with other relevant components of the wider context. 


\section{DEVELOPING SOCIALLY INNOVATIVE POLICY SOLUTIONS}

Addressing the complex and multi-layered social disadvantage experienced by young people demands the development of socially innovative policy solutions. Even though young people in Europe were among the groups affected mostly by the economic recession and the subsequent public sector cuts and austerity measures this did not lead either to a general reconsideration and reconfiguration of the education and transition systems in European countries, nor to a general rethink of the prevailing macroeconomic framework and economic policy approaches. Thus, strong path dependency and institutional inertia seems to prevail even though existing institutional frameworks do not seem able to tackle the growing problems of young people in many countries. This means that the 2008 economic crisis aggravated the inconsistencies and contradictions present in many European education systems and VET regimes, as well as the prevailing dynamics of labour markets and employment relations which in many countries have become dominated by the increase of insecure and precarious forms of employment.

Education systems and VET regimes do not only fulfil functions of social integration and cohesion. They also claim to 'sort' people into different social positions according to merit while reproducing and legitimizing social inequalities based on social background, gender, migration and so on. As demonstrated by the unemployment and NEET rates (Bacher 2014; Eurostat 2015; Thompson 2011) in the current and prolonged situation of economic crisis a considerable share of young people fail to follow the standard path from education or vocational training to sustainable employment and social integration. However, given the currently dominant transformation of Active Labour Market Policies, there is a strong tendency in many countries to create distinctive activation and even 'workfarist' regimes for disadvantaged and marginalized groups. These rely on rather narrow concepts of training and support to integrate young unemployed people into employment - even in precarious forms - as quickly as possible. The understanding of risk taken is also highly individualized (Daguerre 2007; Eriksson and Vogt 2013; Grover and Piggott 2013; Scherschel, Streckeisen and Krenn 2012; van Berkel and Valkenburg 2007). The hegemonic strategic orientation of activation policies in increasingly polarizing or dualizing welfare regimes and labour markets is at the expense of a wider and more sustainable orientation towards education and social integration - which should not start from a work first orientation but rather from a perspective of social integration and participation (Otto et al. 2015). In short, existing policies do not seem 
to live up to the challenges posed by the situation of disadvantaged young people in Europe today.

\section{KEY QUESTIONS AND ANALYTICAL FRAMEWORK}

It is in this context that this volume seeks to examine youth inequalities and suggest, drawing on extensive empirical research in European countries, how social and institutional opportunities can be created in order to better enable young people to live lives they have reason to value. The structure of this volume is organized along the following four sets of questions and analytical steps.

First, policy understandings of youth disadvantage are thoroughly explored and their normative assumptions challenged. Dominant strategies of youth-related policies in relation to labour market integration, VET and social integration are increasingly dominated by an individualized demand to activate oneself. This normative assumption is unpicked and critiqued. Questions are raised as to whether they satisfactorily explain and tackle youth inequalities. Which relevant explanatory factors are left out and which ones are given too strong an emphasis? For this analysis the Capability Approach as developed by Amartya Sen (1990, 1992, 1999a, 1999b) and Martha Nussbaum (2001) (see below) will be developed further and expanded to serve as an evaluative tool for a critical understanding of youth-related policies.

Second, moving from this policy perspective and institutional analysis, attention is turned to the voices and aspirations of the young people themselves, considering not only young people's voices in the context of policy development but also in the context of their daily lives. Thus, this analysis looks at whether and how young people are given voice in policymaking processes and implementation across Europe. What are young people's aspirations, and to what extent are they allowed to voice these aspirations and make them count when decisions are made about their lives? Do policy-makers, schoolteachers, social workers and other practitioners take serious account of young people's voices, views and opinions? Are some young people marginalized to the point that their voices are not given due attention?

Third, participatory research is used to address these issues, making of the empirical work presented in this volume, micro-participative investigations which strengthen young people's voices. These investigations are an important part of the material presented in this volume, as they provide much insight into what capability-friendly youth policies should look like. All in all, the very purpose of this volume is to extend and build knowledge 
in order to develop socially innovative policy to address social disadvantage amongst young people in Europe.

In the fourth step, the critical analysis of existing policies for young people as well as the insights and conclusions from the participatory research activities are brought together to develop an in-depth and thorough discussion of crucial elements for a comprehensive reorientation of social policies for young people to tackle disadvantages and social inequalities and to empower them to live the life they have reason to value. Against the background of the preceding empirical analysis, elements of a much more encompassing concept of social policy and social integration are analysed through a discussion of the concept of equality in the light of the Capability Approach. To deepen this extension of the conceptual underpinnings of a capability oriented social policy, the significance of young people's aspirations and their capability to aspire as a precondition of social integration will be discussed on the one hand. On the other hand the development of transformative forms of participation in policymaking and implementation will be discussed as a tool to make young people the subject of social integration and the fight against social disadvantage and inequality.

The analysis presented in this volume is framed by these questions and analytical steps, in order that conclusions concerning future roads towards designing and implementing more adequate policies, based on a participatory research strategy and the mobilization of the Capability Approach, can be drawn. The original contribution of the book lies mainly in its focus on youth participation and in its mobilization of the Capability Approach.

A key premise of the analysis is that participation is a crucial element of socially innovative policymaking as young people cannot be seen as objects of change but rather they ought to be envisaged as the co-producers of change. Hence, it insists on taking the EU Youth Strategy's particular emphasis on encouraging young people to actively participate in society in terms of their democratic and political participation seriously (European Commission 2009). This means the participatory research strategy adopted in the contributions to this volume acknowledges the importance of taking into account the views of young people, and the need for their active involvement in the development, monitoring and implementation of policy. The conditions for the effective participation of young people are very demanding. Not only are young people allowed to express their views and wishes, but these have to be taken seriously and should have an effective impact on decision-making processes and on the content of policies.

This implies, for instance, that young people's participation is promoted not only in formal arenas such as youth parliaments, but in all institutions or groups where they have a stake: schools, companies, families and so on. 
This also requires that young people be genuinely listened to when they express their views. In many instances, decision-making bodies use their own language and young people feel alienated in such arenas (Lightfoot and Sloper 2003; Mallan and Greenaway 2011; Tisdall 2011; Vromen and Collin 2010). One further requirement is that all young people's voices are taken seriously, that is, not only the voices of the most skilful deliberators that are able to advance their views and defend them, but also those of more disadvantaged young people in this respect. These are but a few examples that illustrate the size of the challenge ahead if young people's participation is to be taken seriously and not just as a rhetorical aim or wishful thinking. The analysis presented in this volume strives to identify precisely and thoroughly the conditions required if youth participation is to make a difference in the sense of designing policies and interventions to tackle youth disadvantage more efficiently.

\section{THE CAPABILITY APPROACH}

The analysis presented in this volume mobilizes the Capability Approach as a normative and analytical yardstick to assess the situations of disadvantaged young people and the policies designed to support them, as well as suggest avenues for reforming them. Through the Capability Approach, knowledge is built in order to develop capabilities informed, and socially innovative, policy so that disadvantaged young people living in different European countries today can achieve a 'good life'. Thus, the Capability Approach, as developed by Amartya Sen (1990, 1992, 1999a, 1999b) and Martha Nussbaum (2001), provides an extremely fruitful framework for addressing youth inequalities.

Along this analytical line, the main criterion used to assess youth policies and programmes is the following: to what extent do such policies or interventions contribute to enhance young people's freedom to lead a life they have reason to value? This encompasses two complementary dimensions (Bonvin and Moachon 2008; Bonvin and Orton 2009). The first relates to the means provided to young people, in terms of resources (cash or in-kind benefits), qualifications or education (training programmes provided via school or the like) as well as opportunities to participate in the labour market, in education and in society. If young people are deprived of such resources, qualifications and competencies and if they are entrapped in an unfriendly environment that does not entitle them to lead a life they have reason to value, then the enhancement of their capabilities is missed. In this respect, one could say that the financial crisis of 2008 has deeply deteriorated the amount and level of resources available 
for young people (especially via austerity measures) and has contributed to create an environment where the development of their capabilities is made more difficult, as is illustrated by the unemployment and NEET figures presented earlier in this chapter. In the absence of adequate resources and of a capability-friendly environment, the focus that some countries put on the development of human capital proves insufficient to get young people out of the unemployment or the 'NEET trap'. Indeed, the Capability Approach insists that the whole configuration of adequate resources, enhanced human capital and appropriate social and environmental parameters is needed in order to develop young people's capabilities. As such, it provides a relevant yardstick to assess the impact of the financial crisis and the austerity measures that followed. The second dimension of the Capability Approach designates young people's real freedom to choose a way of life they have reason to value and depends, largely, on their ability to participate and make their voices heard and taken into account when decisions about their lives are made. This requires, on the individual side, cognitive and political skills (that is, the ability to produce knowledge about one's situation and the parameters that account for it, together with the faculty to efficiently represent and push these views in the decisionmaking arenas). However, these are not enough per se, they need to be accompanied by the readiness of the institutions to include the viewpoints of all relevant stakeholders, in our case the young people, and to take these views seriously. Hence, freedom of choice is not only a matter of being a skilful deliberator, it is also a matter of being allowed to speak one's voice and being taken seriously while doing so. If young people are to lead lives they have reason to value, their voice needs to be taken seriously. Here again, the financial crisis did not increase the readiness of institutions to include, and take serious account of, young people's views about their situations. On the contrary, the unilateral focus on financial equilibrium and austerity was imposed on all stakeholders, thus preventing and making inaudible to a large extent the expression of alternative viewpoints.

The two dimensions of the Capability Approach - empowerment and the provision of adequate means and context on the one hand, freedom to choose lives one has reason to value on the other hand - are interdependent insofar their disjunction leads either to paternalism (lots of means may be provided to promote young people's capacity to act, but no freedom may in fact be granted to them as to how they should use it) or to purely formal freedom (the importance of young people's life choices is promoted, but young people are not provided with the means, that is, the resources, competencies and opportunities, for implementing them). The analysis in this volume strives to avoid these two pitfalls - paternalism and formal freedoms - and to identify the conditions for promoting the development 
of all young people's capabilities, whatever their social origin, nationality, gender, level of education and so on. To identify the individual, social, economic, political and so on prerequisites that are needed for young people to be able to lead a life they have reason to value, is the key analytical and normative challenge tackled in this book.

The following aspects are particularly emphasized throughout the volume. First, the enhancement of capabilities is not a matter of individual responsibility only, that is, young people alone, by themselves will not solve the problem. Young people need to be supported by public policies and programmes in order to be able to lead a life they have reason to value. However, these policies cannot be the same in all national and local contexts; they are to be defined in accordance with their specific features. Drawing on a thorough empirical investigation of national and local contexts, this volume insists on the necessity of situated and contextualized approaches to the development of young people's capabilities. Second, if young people's capabilities are to be promoted in the sense of something they have reason to value, then their aspirations and wishes need to be included in the decision-making processes resulting in youth policies. This point emphasizes the importance and relevance of young people's lived experience when designing programmes or interventions for them. One could say, paraphrasing the motto used by the disability rights movement, 'Nothing about young people without young people'.

This clearly shows the interdependence between the Capability Approach and the focus on participation as a lever for social innovation, which creates a social benefit. It requires departing from technocratic approaches to policymaking, where the views of experts tend to prevail over those of other stakeholders to the point of sometimes discarding or excluding them. Such technocratic views indeed imply that the information deemed as relevant when framing a public issue, is selected by experts or by civil servants without any public or collective debate about this issue. For instance, if experts consider that youth inequalities are primarily a matter of individual effort (that is, the problem lies in young people's lack of motivation), then all alternative explanations will be discarded. This in turn implies that when information is gathered about the situation of disadvantaged young people, the focus will be placed on the specific dimension identified by the experts: do these young people act in a way and make the effort that is expected of them?

By contrast, the involvement of other actors, including young people, at this very early stage - that is, when problems are framed and informational bases selected - allows a more contrasted and complex view on the situation of young people, emphasizing not only their effort, but also other socio-structural parameters such as their social origin, the state of the 
labour market, the prevalence of discriminatory behaviours against young people or against some categories of the population and so on. This point illustrates the very high relevance of the way the 'Informational Basis' (IB) (Sen 1990) of a policy is selected. Indeed, whether this selection is made by experts alone or in the presence of young people and other actors makes a huge difference with regard to the diagnosis made and, in the end, the content of public action. This volume pays special attention to these IB selection processes: who is involved? Are young people included? If yes, are all young people involved, regardless of their social origin, nationality, gender and so on? It sheds light on the consequences of technocratic IB selection processes and explores the possibility of more innovative processes giving voice to all actors involved.

\section{OVERVIEW OF THE CHAPTERS}

Through the Capability Approach a much wider perspective on youth disadvantage and the ways to tackle it can be proposed; this is the very purpose of this volume. In conceptual terms, such a perspective calls for a thorough reframing of issues that are central in contemporary social policies, such as inequality and participation, aspirations and capability to aspire, or the relevance of paternalism in interventions aiming at enhancing the autonomy of vulnerable youth. By applying the Capability Approach, a much wider perspective on youth disadvantage in terms of training and employment, that emphasizes young people's voice and participation, is proposed. The analysis presented in this volume proceeds according to the following steps.

Part I aims to show the benefit of a Capability Approach in social policy analysis. In empirical terms, the analysis presented in the chapters reveals that it requires paying attention not only to outcomes but also to processes. It insists that, beyond questions of efficiency, issues related to the informational basis of policies, that is, their normative and cognitive foundations are highly relevant when it comes to assessing them. Thus, the purpose of Part $\mathrm{I}$ is to examine the normative assumptions that underpin policy. It is demonstrated that current policy does not account for the intersectional or cumulative nature of disadvantage. It suggests a different exploitation of existing statistical data, oriented towards the enhancement of the quality of life rather than the maximization of quantitative rates such as the employment rate or the like.

Jean-Michel Bonvin, Benoît Beuret and Stephan Dahmen (Chapter 1) argue that the question 'equality of what?' is of central importance for exploring the relation between social justice and inequalities, as it also indicates what should be equalized and what can remain unequal. The design 
of social policies will look differently according to the responses given to this question. What inequalities require state intervention and why? Which ones can be 'neglected'? Who decides about this issue and who is not involved in the identification of unacceptable inequalities? The chapter aims at describing how a capability perspective on social inequalities allows tackling more adequately the complex interaction between inequalities, disadvantage and participation.

Céline Goffette, Josiane Vero, Helen Graham, Robert Raeside, Enrica Chiappero-Martinetti, Alberta M.C. Spreafico and Agnese Peruzzi (Chapter 2) investigate how the education, employment and lived experiences of young people in Europe have changed over the economic crisis period, offering a statistical portrait of the situation of young people from a capability-oriented approach. They ask how, and in what areas, inequalities in capabilities have worsened, and consider how the economic crisis exacerbated the difficulties faced by young people in gaining access to the labour market and having the freedom to choose jobs that they have reason to value. They consider the divergence in youth participation in education, in the labour market, and at large within and across regional clusters, arguing that consideration needs to be given to the regional contexts in which young people operate.

Thierry Berthet and Véronique Simon (Chapter 3) analyse French local public policies fighting early school leaving from the point of view of case managers and young people. They show a gap between the 'social contract' perspective inspiring public policies and the concrete inequalities and vulnerability affecting young people. As a result, the success of these policies is interpreted as largely dependent on behavioural expectations towards the beneficiaries. The chapter shows that case managers conceive participation of young people in public policies in terms of motivation and active behaviour. A methodological insight on how to tackle the beneficiaries' concrete experience of policy programmes by using specific fieldwork methods is also provided.

Christian Christrup Kjeldsen (Chapter 4) provides insights in the development of a scale and models on quality of life inspired by the Capability Approach. Drawing on a quantitative comparison of five countries (UK, Romania, Italy, France and Denmark), it implements a multilevel analysis on a composite constructed Subjective Capability Quality of Life Scale (SCQL Scale). The choice of items for this scale is informed by the normative idea of justice found in the Capability Approach. The analysis is conducted on secondary data found within the European Quality of Life Survey (EQLS). It is argued that one uniform composite measure cannot stand alone; rather, due to the relational nature of the Capability Approach, a broader model is needed. 
Sergio Belda-Miquel, Alejandra Boni Aristizábal and Aurora LópezFogués (Chapter 5) focus on Spanish policies and argue that they do not adequately address the situation of youth facing multiple disadvantages. Based on Sen's idea of democratic participation, the chapter analyzes the perspectives of different stakeholders on youth disadvantage, as well as it inquires to what extent theses perspectives are taken into account when policies are designed. Evidence shows that Spanish youth policies have a too narrow approach and leave out important dimensions of disadvantage. This situation is aggravated by young people's lack of participation in the policy design, the lack of coordination among government levels, austerity measures as well as short-term partisan interests.

The chapters in Part II examine the effectiveness and contradictions in the training and employment policies for disadvantaged young people in Europe from the perspective of the Capability Approach. The chapters demonstrate that current approaches have tended to focus on individual attributes and deficits, and do not take a wide and nuanced view of the nature of labour market disadvantage (although there may be disparities between policy frameworks at the macro level, and their delivery at the meso and micro level). In addition, policies, which focus on headline indicators such as the youth unemployment rate, are not oriented towards the enhancement of the quality of life, which has deteriorated since the economic crisis. By applying the Capability Approach, a much wider perspective on youth disadvantage in terms of training and employment, that emphasizes young people's voice and participation, is proposed.

Roland Atzmüller and Alban Knecht (Chapter 6) analyse the ambivalences and contradictions of the Austrian Youth Guarantee and its evolution towards a training obligation. It reveals how this policy is increasingly drawn towards workfarism, which is accompanied by a polarizing, fragmenting style of welfare policies. In this context the chapter shows how experts legitimize and justify the emerging set of increasingly mandatory, workfarist policies by emphasizing the necessity of remodelling youth subjectivities which are understood to be immature, deficient, irrational and, at times, downright crazy. In the paternalizing view of the experts, the youth guarantee (and the supra-company apprenticeships as institutional implementation) stands for rational interventions, which follow the social investment model.

Giuseppe Acconcia and Paolo Roberto Graziano (Chapter 7) examine whether young people's participation in policymaking leads to an enhanced capability to aspire in reference to the implementation of the 'Youth Guarantee' (2014-2020) in Italy. They identify the driving factors for the differential impact of participation on policy integration through two case studies, drawing upon semi-directive interviews and focus groups. They 
argue that socially innovative policy can be produced by strengthened participation in policymaking processes - but at present there is limited integration of young people in policymaking processes.

Stephan Dahmen, Jean-Michel Bonvin and Benoît Beuret (Chapter 8) continue with this theme of voice, integration and participation in providing an analysis of the continuity and change of Swiss youth policies. They describe the emergence of new categories of public action and the dynamic interplay of different actors for the institutionalization of these categories. Dahmen and colleagues argue that the restructuring of youth policies is, in organizational terms, subject to a field of struggle containing both bottom-up and top-down processes. They demonstrate that the call for more youth participation in soft policy fields is accompanied by reforms in social policies by which young people are affected the most.

Robert Raeside, Valerie Egdell and Helen Graham (Chapter 9) turn to examine the attitudes of those responsible for the development and/or implementation of employment activation policies for young people in Denmark, France, Italy, Romania and the UK. Considering the barriers and challenges to young people integrating into, and participating in, society, Raeside and colleagues consider whether agents perceive barriers to young people's integration into, and participation in, society as only affected by individual factors; or whether they perceive that there are wider social and economic constraints. Drawing on the results of innovative Q-method interviews, the hidden preferences of the agents responsible for the development and implementation of policy are revealed. Conclusions are made concerning the implications of variations in attitudes in terms of the ways in which policy might be implemented on the ground.

Céline Goffette and Josiane Vero (Chapter 10) argue that while the policy focus has been on the headline youth unemployment rate, little or no attention has been on young people's job quality. Using data from the European Union Labour Force Survey, they shed light on involuntary part-time employment as well as involuntary temporary employment and their determinants. They apply the Capability Approach to understand how individual and environmental factors interactively affect processes that lead to involuntary part-time or temporary work. In doing this they highlight that active labour market policies, which see work as an ideal functioning, are not capability friendly if no account is taken of job quality.

After a range of detailed and thorough critiques of existing policies concerning disadvantaged youth, Part III focuses on the significance and potentials of participation as a collective and transformative approach to research activities as well as public policies concerning the situation of (disadvantaged) youth. Two perspectives are taken into account. On the one hand, the chapters analyse the strengths and advantages of participatory 
research activities in creating a deeper and more encompassing picture of the situation of (disadvantaged) youth through making them the subject of the very process of knowledge creation. Instead of constructing and positioning (disadvantaged) youth as objects of research, participatory research strategies aim at giving young people the space to co-construct the process of knowledge creation about them. Thus, they are not just asked to contribute to research through their experiences but rather they are empowered to decide about the problems and questions to be researched, the strategies of operationalization as well as the creation and analysis of in-depth knowledge and insights. Through participation, research not only becomes capable of transforming the Informational Basis of Judgement and Justice (Sen 1990) which lies at the heart of the policy processes but it also opens up collaborative and collective processes which can contribute to social transformation. Thus, on the other hand the chapters shed some light on the significance of participation of young people in the process of designing, implementing and evaluating policies that aim at supporting them and tackling disadvantage. Participation conceptualized as a collaborative and transformative capability is revealed as a strategy to give (disadvantaged) young people the opportunity and possibility to occupy and create their space in society, which would allow them to live lives they have reason to value and flourish.

Thomas Ley (Chapter 11) discusses a subject-orientated approach to participation from a capability perspective. Ley argues that while the prevalent definitions of participation are classifying types and degrees of participation and its decision-making processes into different levels (that is, the ladder of participation) and thus falling back into the less helpful (expertocratic) differentiation of participation and non-participation and the exaggeration of autonomy; it seems useful to elaborate a persistent subject orientated (but not individualistic) approach to participation from a capability perspective. Participation - in its subject-orientated sense - can be defined as a special form of human acting, which (tries to) influence the situation as a whole (from the perspective of the subject) and therefore the perpetuation or increase of the quality of life is tackled and aspired.

In their second chapter in this volume Véronique Simon and Thierry Berthet (Chapter 12) debate contradictory, collective and participative policy analysis and the Capability Approach as an approach to give voice to young people through participatory methods. They show the implementation of a specific method to highlight how some programmes that aim at fighting 'dropping out' can miss their target and objectives. To do this, they adapt, reframe and rename the methodological tool of sociological intervention (SI) as CCAPPA (for Contradictory, Collective and Participative Policy Analysis), to create a powerful tool to structure a reflexive point of 
view by young people and to analyse their experience of these programmes. Through the application of CCAPPA Simon and Berthet are able to reveal how the failure to take into account the life and values of young people participating in such programmes against drop out and early school leaving undermines the ability of these programmes to reach their goals.

Bettina Haidinger (Chapter 13) recapitulates the guiding principles of feminist youth work in the light of the Capability Approach and Fraser's concept of participatory parity. Girls work and gender sensitive pedagogics in youth work have become state-of-the-art principles in professional social work with young people. It is widely acknowledged that girls and boys are using different offers of (local and public) support and leisure activities. From this Haidinger discusses challenges of contemporary gender-sensitive youth work taking into account current projects and discourses with, for and about girls. The chapter draws on empirical evidence from a case study on gender-sensitive youth work in Vienna using a participatory field access.

The chapter by Niels Rosendal Jensen and Anna Kathrine Frørup (Chapter 14) focuses on the aspirations of young people living in disadvantaged areas in Denmark. They examine young people's possibilities, aspirations and demands and the ways they are raised, strengthened, transformed or put aside within different local programmes. The chapter shows that integration is an overall goal defined and carried out very differently among young people who do not feel they have equal and workable possibilities to participate and be included on a local, as well as, societal level. Using Sen's and Nussbaum's concept of capability the chapter focuses on the question of whose willpower is behind young people's voices and aspirations. The chapter shows that local innovative procedures and programmes mainly support the development of new instruments, measures and their realization and to a much lesser extent support young people's capability to participate and to perform practical reasoning as well as real freedom.

In the concluding section of this volume, the key arguments made in the preceding sections are drawn together. Conclusions are made about developing capability oriented youth policies to fight inequality and disadvantage, and developing young people's capability to aspire and to participate.

In the opening chapter of this concluding section (Chapter 15), all contributors to the volume consider the policy implications raised throughout the volume and propose stepping stones towards a capability-friendly youth policy for Europe. They especially emphasize the importance of giving full recognition to young people's aspirations and to promote their effective participation in decision-making processes. These two key issues are further elaborated in the two final chapters of the volume. 
Evelyne Baillergeau and Jan Willem Duyvendak (Chapter 16) focus on young people's aspirations and capacity to frame a desirable future. While social scientists often focus on aspirations as such, they argue that it is necessary to question people's capability to aspire, which is strongly contingent on a wealth of factors beyond the command of individuals. Subsequently, the aspirations of young people and their capability to aspire are discussed along the ways they relate to social inequality. In particular, the common sense of a 'necessary' transition from idealistic to realistic aspirations with the passing of age is put under scrutiny, by showing that there is nothing 'natural' about this transition but that it is strongly dependent on power and resources.

Caroline Vandekinderen, Griet Roets, Hilde Van Keer and Rudi Roose (Chapter 17) discuss participation and participatory research from a capability perspective. The Capability Approach is made operational as a frame of reference to theorize participatory research as a process of knowledge construction and production, and therefore, as a practice of reflection, which requires scrutiny and reflexivity by the researcher. Based on the theoretical perspective of the Capability Approach and the interpretative paradigm of Lifeworld Orientation, they argue that the focus of participatory research is on the collection of data for an 'alternative' - in the sense of deepened and broadened - informational basis for social policy. As such, participatory research is not about 'capturing the authentic voice of disadvantaged young people', but rather evolves as a complex research venture that guards its relation to the conditions in which the voices of social agents unfold. Vandekinderen and colleagues argue for dialogical representational practices that reside in contradictory and constantly shifting and changing interpretations, since the confluence of interpretations can create novel understandings, provoke new questions, generate innovative knowledge and enable new thinking. As such, this chapter provides insightful reflections illustrating along which paths capability-friendly public policies ought to develop.

\section{NOTES}

1. With the exception of Greece, data on the social and labour market situation of young people are taken for countries of the SocIEtY consortium (Austria, Belgium, Denmark, France, Germany, the Netherlands, Romania, Spain, UK).

2. All data are taken from http://ec.europa.eu/eurostat/statistics-explained/index.php/ Labour_market_and_Labour_force_survey_(LFS)_statistics.

3. This volume draws upon research conducted in the 'Social Innovation - Empowering the Young for the Common Good (SocIEtY)' project, funded by the European Commission (2013-2015, Grant agreement number: 320136). The project involved 13 universities and research institutions from 11 different European countries (Germany, UK, France, 
Denmark, Italy, the Netherlands, Belgium, Spain, Romania, Austria and Switzerland). The aim of SocIEtY was to explore how young people aged between 15 and 24 years live in different European countries; and examine what could be done to create social and institutional opportunities which will better enable them to live lives that they have reason to value.

\section{REFERENCES}

Bacher, J. (2014), Unterstützung der arbeitsmarktpolitischen Zielgruppe 'NEET': Studie von ISW, IBE und JKU im Auftrag des Bundesministeriums für Arbeit, Soziales und Konsumentenschutz, Vienna: Verl. des ÖGB.

Blossfeld, H.-P., S. Bertoloni and D. Hofäcker (eds) (2011), Youth on Globalised Labour Markets: Rising Uncertainty and its Effects on Early Employment and Family Lives in Europe, Opladen: Farmington Hills.

Bonvin, J.M. and E. Moachon (2008), 'Social integration policies for young marginalised: a capability approach', Social Work \& Society, 6(2), 296-305.

Bonvin, J.M. and M. Orton (2009), 'Activation policies and organisational innovation: the added value of the capability approach', Journal of Sociology and Social Policy, 29(11/12), 565-574.

Coppola, G. and N. O'Higgins (eds) (2016), Youth and the Crisis: Unemployment, Education and Health in Europe, London: Routledge.

Daguerre, A. (2007), Active Labour Market Policies and Welfare Reform: Europe and the US in Comparative Perspective, New York: Palgrave Macmillan.

Eriksson, K. and H. Vogt (2013), 'On self-service democracy: configurations of individualizing governance and self-directed citizenship', European Journal of Social Theory, 16(2), 153-173.

European Commission (2009), 'An EU strategy for youth - investing and empowering a renewed open method of coordination to address youth challenges and opportunities: COM(2009) 200 final', accessed 10 November 2016, at aei.pitt. edu/42318/1/com2009_0200.pdf.

Eurostat (2015), 'Being young in Europe today', accessed 10 November 2016, at ec.europa.eu/eurostat/documents/3217494/6776245/KS-05-14-031-EN-N.pdf/18b ee6f0-c181-457d-ba82-d77b314456b9.

Groenemeyer, A. and D. Hoffmann (eds) (2014), Jugend als soziales Problem soziale Probleme der Jugend: Diagnosen, Diskurse und Herausforderungen, Weinheim: Beltz Juventa.

Grover, C. and L. Piggott (2013), 'A commentary on resistance to the UK's work experience programme: capitalism, exploitation and wage work', Critical Social Policy, 33(3), 554-563.

Lightfoot, J. and P. Sloper (2003), 'Having a say in health: involving young people with a chronic illness or physical disability in local health services development', Children \& Society, 17(4), 277-290.

Mallan, K. and R. Greenaway (2011), 'Radiant with possibility': involving young people in creating a vision for the future of their community', Futures, 43(4), 374-386.

Nussbaum, M.C.(2001), Women and Human Development: The Capabilities Approach, Cambridge: Cambridge University Press.

Otto,H.-U., R. Atzmüller, T. Berthet, L. Bifulco, J.M. Bonvin, E. Chiappero-Martinetti, 
V. Egdell, B. Halleröd, C.C. Kjeldsen, M. Kwiek, R. Schröer, J. Vero and M. Zielenska (eds) (2015), Facing Trajectories from School to Work, Cham, Heidelberg, New York, Dordrecht, London: Springer.

Saraceno, C. (2015), 'A critical look to the social investment approach from a gender perspective', Social Politics: International Studies in Gender, State \& Society, 22(2), 257-269.

Scherschel, K., P. Streckeisen and M. Krenn (eds) (2012), Neue Prekarität. Die Folgen aktivierender Arbeitsmarktpolitik - europäische Länder im Vergleich. Labour Studies, Band 2, Frankfurt/Main/New York: Campus.

Sen, A. (1990), 'Justice: means versus freedom', Philosophy \& Public Affairs, 19(2), $111-121$.

Sen, A. (1992), Inequality Reexamined, Oxford: Oxford University Press.

Sen, A. (1999a), Commodities and Capabilities, New Delhi: Oxford University Press.

Sen, A. (1999b), Development as Freedom, Oxford: Oxford University Press.

Thompson, R. (2011), 'Individualisation and social exclusion: the case of young people not in education, employment or training', Oxford Review of Education, 37(6), 785-802.

Tisdall, K. (2011), Children and young people's participation in policy-making: making it meaningful, effective and sustainable. Briefing 1, December 2011, Edinburgh: Centre for Research on Families and Relationships.

van Berkel, R. and B. Valkenburg (2007), 'The individualisation of activation services in context', in R. van Berkel and B. Valkenburg (eds), Making it Personal: Individualising Activation Services in the EU, Bristol: Policy Press, pp. 4-19.

Vromen, A. and P. Collin (2010), 'Everyday youth participation: contrasting views from Australian policymakers and young people’, Young, 18(1), 97-112. 
Hans-Uwe otto, Valerie Egdell, Jean-Michel Bonvin, and Roland Atzmüller - 9781788110860 Downloaded from PubFactory at 04/26/2023 08:57:57AM 